\title{
Pengembangan Aplikasi Fasilitas Sosial Berbasis Mobile
}

\author{
Rinda Cahyana $^{1}$, Rizki Maulana ${ }^{2}$ \\ Jurnal Algoritma \\ Sekolah Tinggi Teknologi Garut \\ Jl. Mayor Syamsu No. 1 Jayaraga Garut 44151 Indonesia \\ Email : jurnal@itg.ac.id \\ 1rindacahyana@itg.ac.id \\ 21606096@itg.ac.id
}

\begin{abstract}
Abstrak - Informasi fasilitas sosial merupakan sumber daya penting yang menunjang industri pariwisata dan pendukungnya. Kemudahan akses informasinya dapat diwujudkan melalui teknologi informasi. Penelitian ini bertujuan untuk mengembangkan aplikasi mobile yang dapat digunakan oleh pengguna untuk mengakses informasi fasilitas sosial. Tahapan pengembangannya meliputi inception, elaboration, dan construction. Aplikasi yang dihasilkan oleh penelitian ini menyajikan informasi masjid dan rumah sakit kepada penggunanya.
\end{abstract}

Kata Kunci - Aplikasi Bergerak; Fasilitas Sosial; Masjid; Rumah Sakit.

\section{PENDAHULUAN}

Dalam kerangka kerja masyarakat TIGER, keberadaan pemerintah, pendidikan, dan keagamaan mendukung industri pariwisata dan pendukungnya [1][2]. Pelaku wisata memerlukan fasilitas sosial yang disediakan oleh ketiganya. Menurut Kamus Besar Bahasa Indonesia, fasilitas sosial adalah fasilitas pemerintah atau swasta yang disediakan untuk masyarakat, seperti sekolah, klinik, dan tempat ibadah. Wisatawan memerlukan tempat ibadah saat berwisata untuk memenuhi kebutuhan keagamaannya, pegawai pada industri pariwisata memerlukan sekolah untuk membangun kompetensinya, dan keduanya memerlukan klinik bila sewaktu-waktu mengalami masalah kesehatan.

Sebelumnya telah dilakukan penelitian terkait fasilitas sosial. Nurliani dan Cahyana (2015) mengembangkan aplikasi bergerak untuk pencarian lokasi rumah sakit [3]. Saepulloh dan Cahyana (2015) mengembangkan aplikasi web untuk pencarian informasi perumahan [4]. Hasil penelitiannya dilengkapi oleh Sopandi dan Cahyana (2016) dengan menambahkan fitur peta lokasi perumahan [5]. Hakim dan Cahyana (2015) mengembangkan aplikasi web untuk memudahkan pencarian lokasi fasilitas sosial [6][7]. Berbeda dengan penelitian lainnya, informasi yang dicari dapat meliputi rumah sakit, perumahan, dan fasilitas sosial lainnya. Hasil penelitian tersebut dilengkapi oleh Fauzian dan Cahyana (2016) dengan fitur profil fasilitas sosial dan komentar. Selanjutnya, Satria, Cahyana, dan Aulia (2019) mengembangkan katalog elektronik yang menyediakan informasi seputar potensi masjid, salah satu tempat ibadah yang termasuk fasilitas sosial [8][9]. Penelitian ini bertujuan untuk mengembangkan aplikasi bergerak yang menyajikan informasi fasilitas sosial. Peneliti membatasi fasilitas sosialnya hanya masjid dan rumah sakit.

\section{METODOLOGI}

Penelitian ini menggunakan metode RUP (Rational Unified Process) dengan teknik UML (Unified Modeling Language). Tahapannya dibatasi hanya sebatas inception, elaboration, dan construction sebagaimana tampak pada gambar 1. Data masukan untuk aktivitas pengujian berupa data hasil kuesioner yang disebarkan kepada 
masyarakat di wilayah kabupaten Garut menggunakan google form [10][11][12].

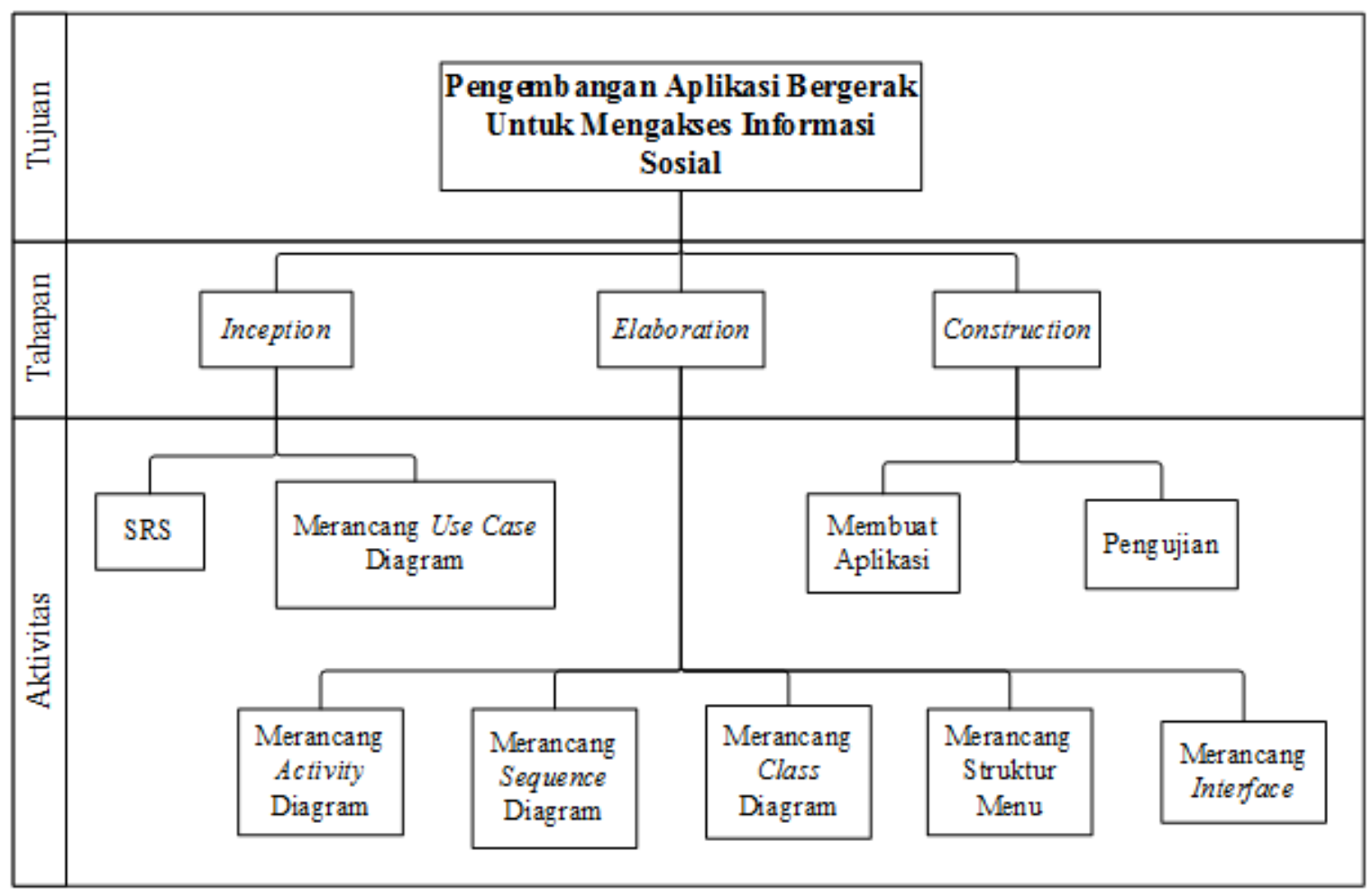

Gambar 1: Work Breakdown Structure

\section{HASIL DAN PEMBAHASAN}

Penelitian ini menghasilkan aplikasi mobile yang dapat dijalankan pada sistem operasi android. Interaksi antara pengguna dengan aplikasi meliputi admin selaku pengelola sistem dan user selaku pengguna aplikasi informasi fasilitas sosial. Admin dapat mengelola data fasilitas sosial meliputi rumah sakit dan masjid, sedangkan user hanya dapat melihat informasi fasilitas sosial sesuai yang ditampilkan dalam aplikasi. Interaksi tersebut ditunjukan sebagaimana tampak pada gambar 2 .

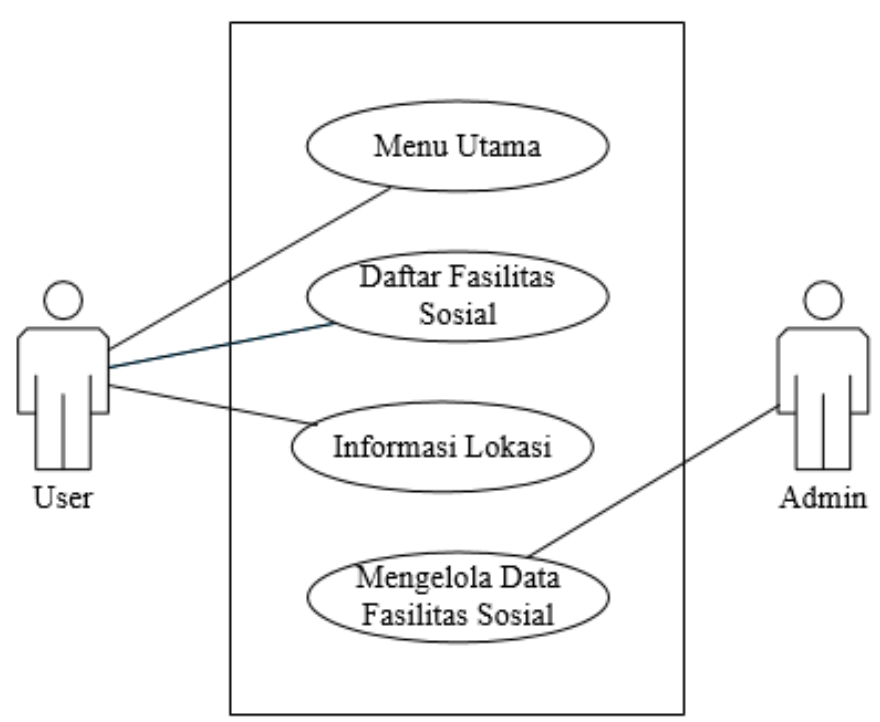

Gambar 2: Diagram Use Case 
Fitur yang tersedia pada aplikasi meliputi informasi dua fasilitas sosial yakni masjid dan rumah sakit, peta lokasi dan petujuk arah. Pada menu utama terdapat empat menu yang disajikan yaitu menu masjid, menu rumah sakit, menu bantuan dan menu tentang sebagaimana tampak pada gambar 3.

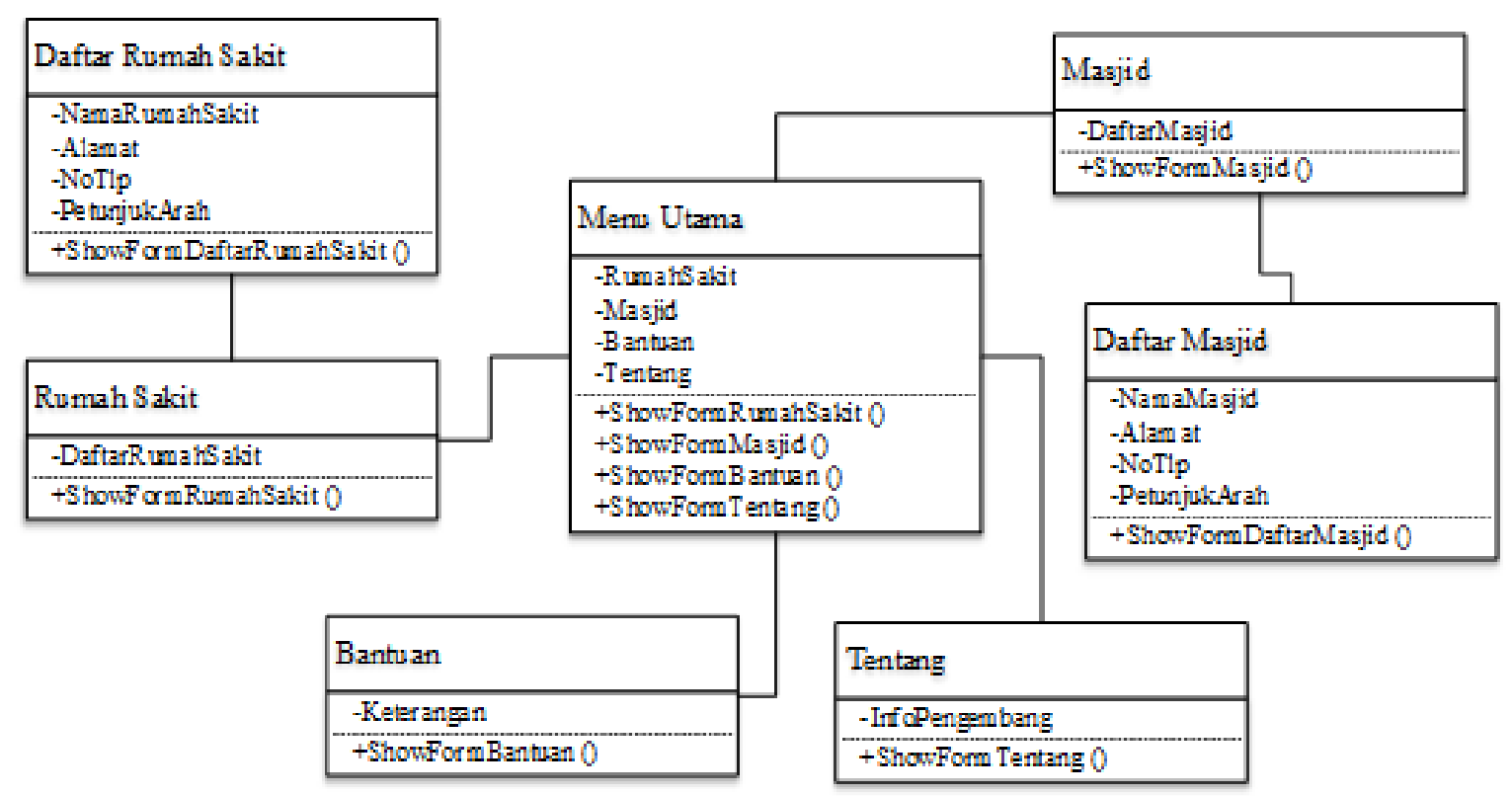

Gambar 3: Perancangan class diagram

Pada saat pengguna membuka aplikasi, sistem akan menampilkan empat menu pada menu utama meliputi menu rumah sakit, menu masjid, menu bantuan dan menu tentang. Pengguna mulai mencari informasi fasilitas sosial yang dibutuhkannya dengan memilih menu masjid ataupun menu rumah sakit. Setelah itu aplikasi akan menampilkan daftar nama fasilitas sosial yang dibutuhkan informasinya sebagaimana tampak pada gambar 4 sampai gambar 7 .

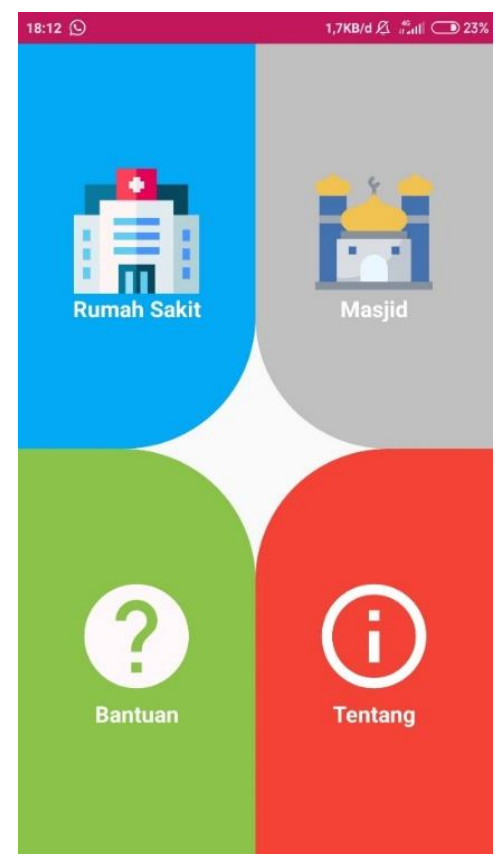

Gambar 4: Antarmuka Home 


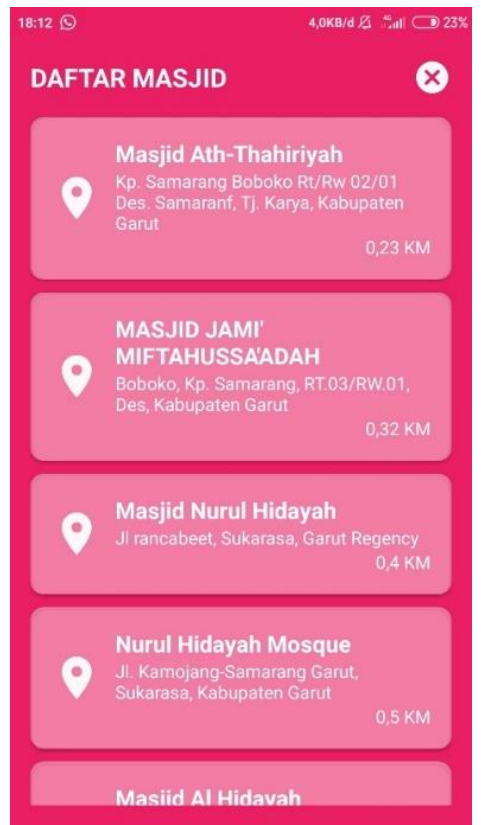

Gambar 5: Antarmuka Menu Daftar Fasilitas Sosial

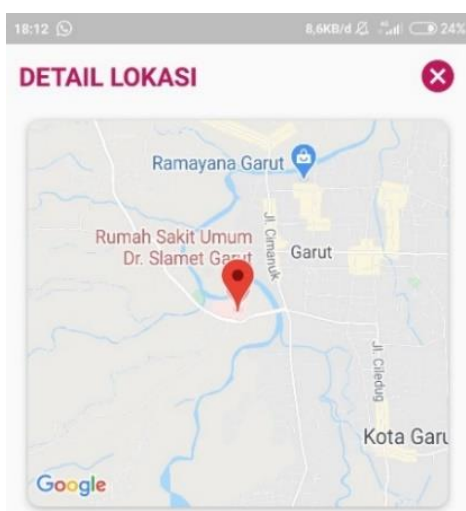

RSUD Dr. Slamet Garut

Jl. Rsu DR. Slamet No.12, Sukakarya, Kec. Tarogong Kidul, Kabupaten Garut, Jawa Barat 44151, Indonesia (0262) 232720

PETUNJUK ARAH

Gambar 6: Antarmuka Detail Lokasi 


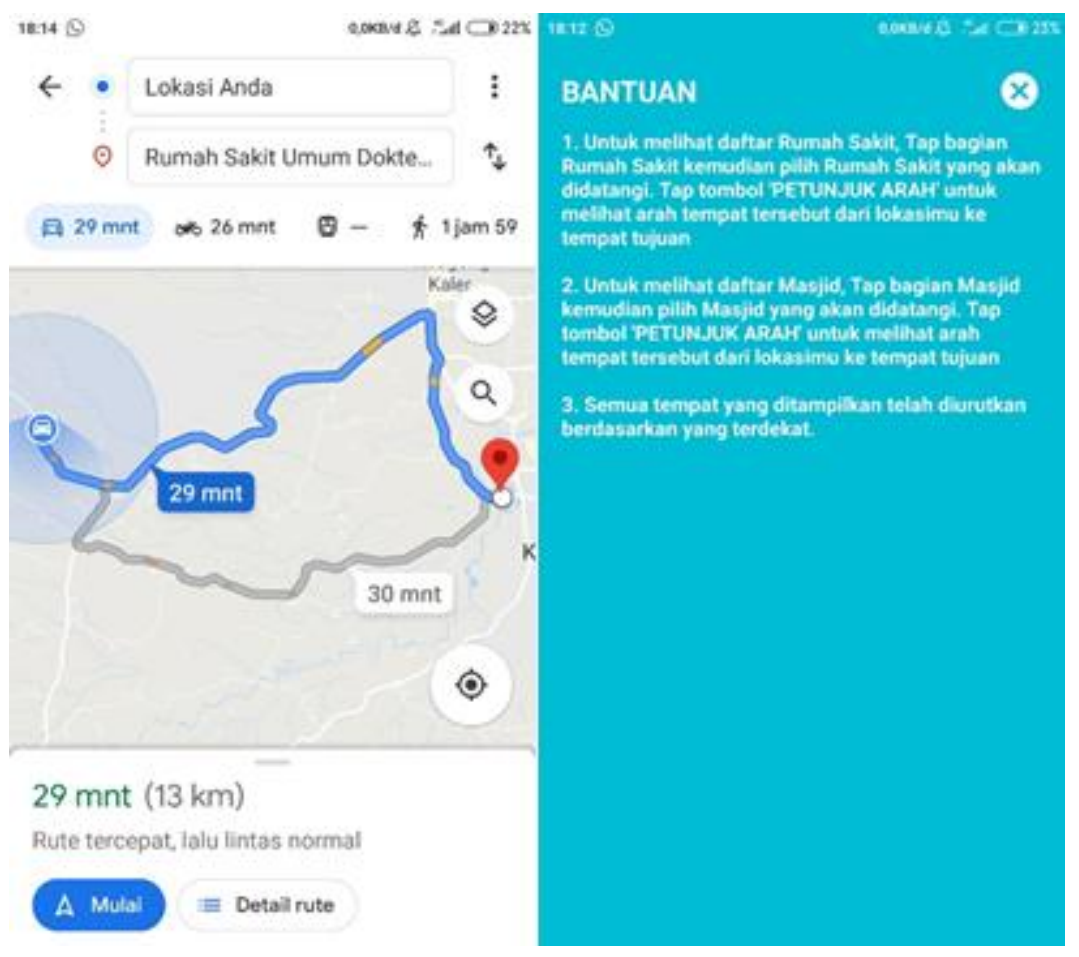

Gambar 7: Antarmuka Aplikasi

Hasil pengujian menunjukkan kenyamanan responden terhadap tampilan keseluruhan pada aplikasi, 78,13\% menyatakan setuju; pengoperasian aplikasi, $100 \%$ menyatakan sangat setuju; penggunaan warna pada aplikasi, $78,13 \%$ menyatakan setuju; penggunaan icon dan simbol, 93,75\% menyatakan setuju; penggunaan font, 59,38\% menyatakan setuju; tata letak gambar, $87,50 \%$ menyatakan setuju; fungsi tombol navigasi, $100 \%$ menyatakan sangat setuju; dan penyajian informasi, 93,75\% menyatakan setuju. Perbandingan antara hasil penelitian sebelumnya dengan penelitian saat ini sebagaimana tampak pada gambar 5 .

\begin{tabular}{|c|c|}
\hline 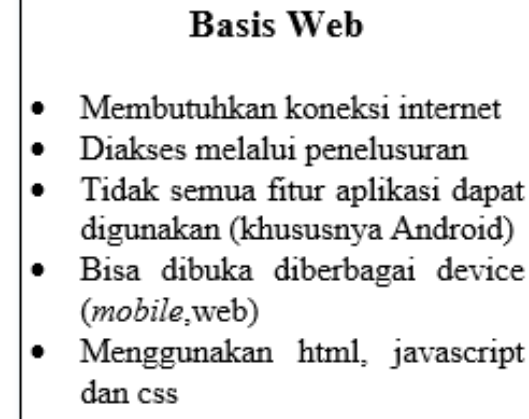 & $\begin{array}{l}\quad \text { Basis Mobile } \\
\text { - Tersedia offline/online } \\
\text { - Diakses setelah aplikasi diinstal } \\
\text { - Dapat menggunakan fitur aplikasi } \\
\text { yang ada di android (GPS) } \\
\text { - Device lebih spesifik (Android) } \\
\text { - Menggunakan bahasa pemrograman } \\
\text { Java. }\end{array}$ \\
\hline
\end{tabular}

Gambar 8: Perbandingan platform

\section{KESIMPULAN}

Penelitian ini berhasil mengembangkan aplikasi bergerak yang menyediakan informasi fasilitas sosial bagi masyarakat yang terbatas hanya pada masjid dan rumah sakit. Hasil pengujian menunjukkan bahwa pengguna secara umum merasa nyaman dengan aplikasi ini. Penelitian ke depan dapat mengubah rancangan aplikasinya agar dapat mengakomodasi fasilitas sosial lainnya. 


\section{DAFTAR PUSTAKA}

[1] W. Roselina, "Aplikasi Berbasis Multimedia Untuk Pembelajaran Hardware Komputer," J. Edik Inform., vol. 1, no. Pembelajaran Hardware Komputer, pp. 70-81, 2015.

[2] R. Cahyana, D. Kurniadi, Y. Pariyatin, and A. Susetyaningsih, "The TIGER society framework in the scope of information technology infrastructure," 2019, doi: 10.1088/1742-6596/1402/6/066102.

[3] H. Nurliani and R. Cahyana, "Pengembangan Aplikasi Bergerak Untuk Penyediaan Informasi Lokasi Rumah Sakit di Wilayah Garut," J. Algoritm., 2015, doi: 10.33364/algoritma/v.12-1.106.

[4] A. Saepulloh and R. Cahyana, "Pengembangan Aplikasi Untuk Penyediaan Informasi Perumahan Secara Online," J. Algoritm., 2016, doi: 10.33364/algoritma/v.12-2.380.

[5] D. Sopandi and R. Cahyana, "Pengembangan Fitur Peta Lokasi Dari Aplikasi Penyedia Informasi Perumahan Secara Online," J. Algoritm., 2017, doi: 10.33364/algoritma/v.13-2.379.

[6] M. Nurul Hakim and R. Cahyana, "Pengembangan Sistem Informasi Geografis Untuk Memudahkan Pencarian Informasi Fasilitas Sosial dan Lokasinya," J. Algoritm., 2016, doi: 10.33364/algoritma/v.122.602.

[7] E. Kurniawan, "Implementasi Rest Web Service Untuk Sales Order Dan Sales Tracking Berbasis Mobile," J. EKSIS, 2014.

[8] E. Satria, R. Cahyana, and N. Aulia, "Electronic catalogue for mapping mosque potencies," 2019, doi: 10.1088/1742-6596/1402/7/077019.

[9] D. Nur Ilham and S. Mulyana, "Sistem Pendukung Keputusan Kelompok Pemilihan Tempat PKL Mahasiswa dengan Menggunakan Metode AHP dan Borda," vol. 11, no. 1, pp. 55-66, 2017.

[10] M. Sutedi; Agarina, "Implementasi Rational Unified Process Dalam Rancang Bangun Sistem Informasi Penjualan Hasil Bumi Berbasis Web Pada Cv. Aneka Mandiri Lestari Bandar Lampung," J. Sist. Inf. dan Telemat., vol. 8, no. 2, pp. 181-187, 2017.

[11] H. Soeroso, S. Sumardiono, H. H. P, M. L. Arif, and M. Miftachudin, "Perancangan Alat dan Mekanisme dalam Menunjang Proses Bongkar Muat Ikan Hidup pada Kapal Ikan di Daerah Brondong - Lamongan," Semin. MASTER PPNS, 2018.

[12] D. D. S. Fatimah, D. Tresnawati, and C. S. Ma'rup, "Perancangan Game Puzzle Untuk Pembelajaran Menggunakan Metodologi Multimedia," J. Algoritm., 2015, doi: 10.33364/algoritma/v.14-2.281. 